\title{
Tribological properties of h-BN nanoparticles as lubricant additive on cylinder liner and piston ring
}

\author{
M. S. Charoo and M. F. Wani*,† \\ Centre for Tribology, Department of Mechanical Engineering, National Institute of Technology, Srinagar, \\ Jammu and Kashmir India
}

\begin{abstract}
Friction and wear behaviour of different concentrations of hex-boron nitride (h-BN) nanoparticles in engine oil of grade SAE 20W50 were studied at various loads. These tribological studies were conducted using a four-ball wear test machine and a pin-on-disc universal tribometer. Anti-wear properties of SAE $20 \mathrm{~W} 50+\mathrm{h}-\mathrm{BN}$ were studied on the four-ball wear test machine as per ASTM D4172 standard. Friction and wear properties of SAE $20 \mathrm{~W} 50+\mathrm{h}-\mathrm{BN}$ on piston ring and cylinder liner tribo-pair were studied using the universal tribometer. Nanoparticles of h-BN mixed in lubricant showed excellent tribological performance. In most of the cases, h-BN nanoparticles as additive reduced the wear loss by $30-70 \%$ at various loads. The minimum value of coefficient of friction $(0.0401)$ was found with SAE $20 \mathrm{~W} 50+3$ wt $\%$ of h-BN at normal load of $100 \mathrm{~N}$. Scanning electron microscopy and Raman spectroscopy were used for characterisation of h-BN and wear scars. Copyright (c) 2016 John Wiley \& Sons, Ltd.
\end{abstract}

Received 2 March 2016; Revised 20 August 2016; Accepted 30 October 2016

KEY WORDS: friction; anti-wear; h-BN nanoparticles; additives

\section{INTRODUCTION}

Lubricants that are produced from mineral oil do not have all the desired tribological properties. It has already been established that addition of solid lubricant particles, such as $\mathrm{MoS}_{2}$, graphite, $\mathrm{WS}_{2}$ and hex-boron nitride (h-BN) to mineral oil improves the tribological properties of lubricants to a large extent. ${ }^{1-8}$ In these research studies, it has been observed that h-BN and other nanoparticles mixed with lubricating oil possess better anti-friction and anti-wear properties, as compared with the base oil, depending on the contact conditions. ${ }^{2-5}$ Recently, researchers have reported that incorporation of nanoparticles with different sizes, either deposited in the form of thin films on the surface of triboelement or as additive in the conventional lubricant in different concentrations, shows reduced friction and wear reduction characteristics. ${ }^{9-14}$

The piston ring and the cylinder liner of an Internal Combustion (IC) engine particularly pose challenges to tribologists, for being a significant source of friction losses in engines. Reduced power

*Correspondence to: Mohammadd Wani, Department of Mechanical Engineering, National Institute of Technology, Hazaratbal, Srinagar, India.

†E-mail: mfwani@nitsri.net

Copyright (C) 2016 John Wiley \& Sons, Ltd. 
loss, low efficiency, high fuel consumption, large wear, high emissions and effective cooling are related to piston ring-cylinder liner interface lubrication. The reduction of wear and friction losses in an IC engine is a function of good lubrication. Studies of the mechanism of piston ring lubrication and related friction phenomena have indicated that piston rings and cylinder liner contribute significantly to the total engine mechanical friction losses. ${ }^{15}$ In general, high friction occurs at, or near, dead centres, i.e. at top dead centre (TDC) and bottom dead centre due to boundary lubrication. This condition is further aggravated at TDC due to the presence of higher temperature.

It is evident from the aforementioned literature review ${ }^{1-8}$ that addition of particular concentration of nanoparticles to the conventional lubricant reduces the friction coefficient and increases the wear resistance. Researchers used different forms of boron nitride as lubricant additives, i.e. microparticles, nanoparticles and nanotubes. ${ }^{2-6}$ However, very little research has been carried out on the effect of $\mathrm{h}-\mathrm{BN}$ as additive in conventional lubricants in practical application, such as piston ring on cylinder liner in an IC engine.

In this research, various concentrations of h-BN as lubricant additive on a piston ring and cylinder liner tribo-pair of an IC engine at various loads are investigated. In the first set of experiments, the effect of h-BN as additive is studied in a four-ball wear test machine. In the second set of experiments, the effect of the h-BN nanoparticles as additive is studied on actual tribo-pair on a universal tribotester.

\section{EXPERIMENT AND MATERIALS}

\section{Preparation of lubricant}

Hexagonal-BN is a lamellar solid just like graphite and has high refractory and lubricity qualities. Its atomic layers are made of two-dimensional arrays of boron and nitrogen atoms. The bonding between nitrogen and boron atoms is covalent and hence very strong, whilst bonding between the layers is primarily van der Waals type and weak.

In these tribotests, h-BN nanoparticles with a diameter of $50 \mathrm{~nm}$ were used, which were mixed with the engine oil Society of Automotive Engineers (SAE) 20 W50 in different concentrations. The nanopowder of h-BN was purchased from Intelligent Materials Pvt. Ltd. (Nanoshel LLC, USA). The h-BN nanoparticles, white in colour, with density of $2.3 \mathrm{~g} \mathrm{~cm}^{-3}$ and melting point of $1200^{\circ} \mathrm{C}$ were added in base engine oil of grade SAE 20W50 in different concentration (weight\% 1.0, 2.0 and 3.0). The h-BN nanoparticles mixed with engine oil was kept in a test tube and stirred for $4 \mathrm{~h}$ using WENSAR ultrasonicator (Bengaluru, Karnataka, India) at a temperature of $50^{\circ} \mathrm{C}$ and frequency of $40 \mathrm{kHz}$ to disperse the nanoparticles uniformly as shown in Figure 1. The properties of the SAE 20W50 engine oil are shown in Table I. There was no significant change observed in the physical and chemical properties of the lubricant SAE 20W50 with the addition of $1.0 \mathrm{wt} \%, 2.0 \mathrm{wt} \%$ and $3.0 \mathrm{wt} \% \mathrm{~h}-\mathrm{BN}$ nanoparticles.

Nanoparticles of h-BN were not surface capped by any active agent. By applying fundamental relation of dynamics, the expression of the steady state sedimentation speed (V) of a particle is obtained ${ }^{17}$ :

$$
\mathrm{V}=\frac{2}{9} \frac{\mathrm{R}^{2}}{\eta}\left(\rho-\rho^{\prime}\right) \mathrm{g}
$$

with 


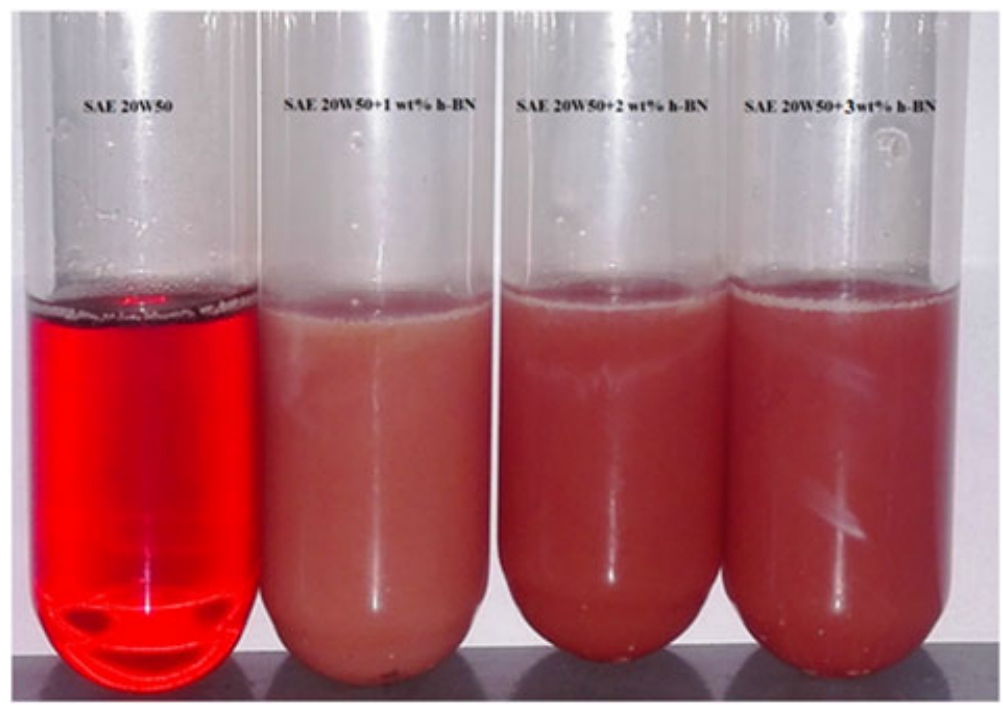

Figure 1. Fully formulated Society of Automotive Engineers (SAE) 20W50 engine oil with hex-boron nitride (h-BN) nanoparticles.

Table I. Properties of lubricant oil grade SAE 20 W50.

\begin{tabular}{lll}
\hline Lubricant properties & Temperature $\left({ }^{\circ} \mathrm{C}\right)$ & \multicolumn{1}{c}{ Value } \\
\hline & 40 & $120 \mathrm{~mm}^{2} \mathrm{~s}^{-1}$ \\
Kinematic viscosity & 100 & $15 \mathrm{~mm}^{2} \mathrm{~s}^{-1}$ \\
Viscosity index & - & 145 \\
Dynamic viscosity & -10 & $2780 \mathrm{mPas}$ \\
Density & 15 & $890 \mathrm{~kg} \mathrm{~m}^{-3}$ \\
Flash point & - & $250^{\circ} \mathrm{C}$ \\
Pour point & - & $-30^{\circ} \mathrm{C}$ \\
\hline
\end{tabular}

SAE: Society of Automotive Engineers.

$\mathrm{R}$ radius of the particle

$\eta$ dynamic viscosity of the lubricant

$\rho$ density of the particles

$\rho$ ' density of the lubricant

The sedimentation distance covered by BN nanoparticles was obtained using Equation 1 and the sedimentation distance covered in $1 \mathrm{~s}$ is $0.025 \mathrm{~nm}$. However, all experiments were carried out immediately after ultrasonication to avoid agglomeration of the nanoparticles dispersed in the lubricant.

\section{Materials}

For conducting experimental studies on universal tribometer, cylinder liner and piston ring pin as shown in Figure 2 was used as tribo-pair. The material for the liner is grey cast iron of G-4000 

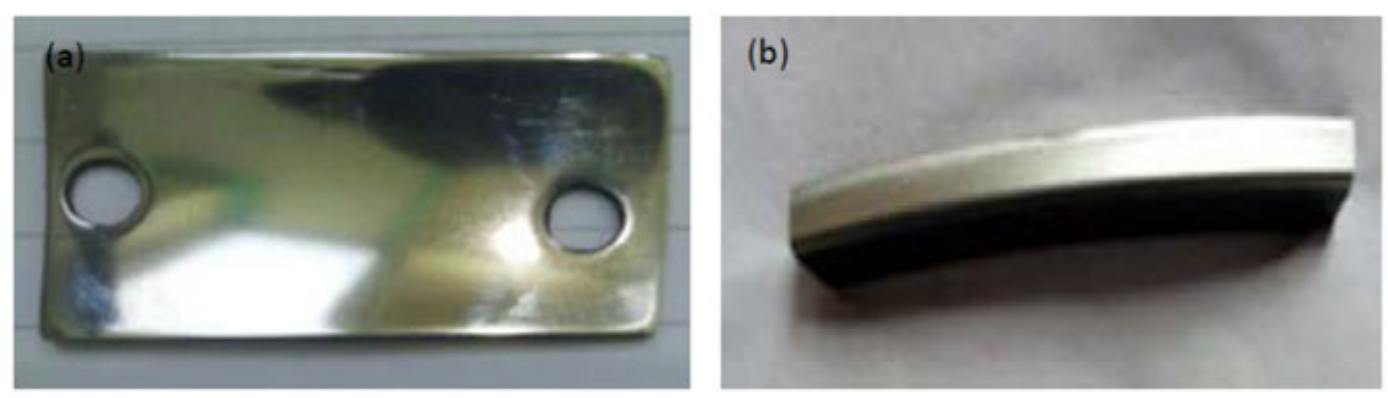

Figure 2. Tribo-pair used (a) cylinder liner and (b) piston ring pin.

grade with density of $7.15 \mathrm{gm} / \mathrm{cm}^{3}$. The cylinder liner was cut in rectangular block of dimension $45 \mathrm{~mm} \times 25 \mathrm{~mm}$, and the piston ring was cut in $3 \mathrm{~mm} \times 4 \mathrm{~mm}$ with curvature along length. The material constituents of cylinder liner and piston ring are mentioned in Table II. Samples were polished, and the average roughness was measured with the help of a surface profilometer. The roughness was measured at four different locations and then averaged for each sample. The average roughness $R_{a}$ value for the cylinder liner samples was $0.1775,0.1905$ and $0.1641 \mu \mathrm{m}$.

\section{Friction and wear tests}

The friction and wear tests for the tribo-pair shown in Figure 2 necessitated the conventional testing of lubricant SAE 20W50 with h-BN nanoparticles as additive using ASTM D4172 standard on a four-ball wear testing machine. There is no standard procedure available for measurement of wear for geometry similar to a piston ring and cylinder liner. Lubricant SAE 20W50 was investigated on a four-ball wear testing machine with and without nanoparticles of h-BN. This method covers a procedure to evaluate anti-wear properties of fluid lubricants in sliding contact. Three $12.7 \mathrm{~mm}$ diameter steel balls made from AISI standard steel No. E-52100 were clamped as shown in Figure 3. The fourth $12.7 \mathrm{~mm}$ diameter top steel ball is pressed with a force of $392 \mathrm{~N}$ into cavity formed by the three clamped balls in the oil cup for three-point contact. The temperature of the test lubricant is regulated by heating element at $75^{\circ} \mathrm{C}$, and the top ball is rotated at $1200 \mathrm{rpm}$ for $1 \mathrm{~h}$. Four-ball wear test machine with a

Table II. Material constituents of cylinder liner and piston ring pin.

\begin{tabular}{lclll}
\hline Cylinder Liner & & & Piston Ring pin \\
\cline { 1 - 2 } Material constituent & Percent $(\%)$ & & Material constituent & Percent (\%) \\
\hline Carbon & $3.0-3.5$ & & Carbon & $0.8-0.95$ \\
Silicon & $1.80-2.80$ & & Silicon & $0.35-0.50$ \\
Manganese & $0.70-1.0$ & & Manganese & $0.25-0.55$ \\
Copper & $0.20-0.50$ & & Chromium & $17-18.50$ \\
Sulfur & 0.15 & & Sulfur & 0.04 \\
Phosphorous & 0.07 & & Phosphorous & 0.04 \\
& & & Molybdenum & $1.0-1.25$ \\
& & & Vanadium & $0.08-0.15$ \\
\hline
\end{tabular}




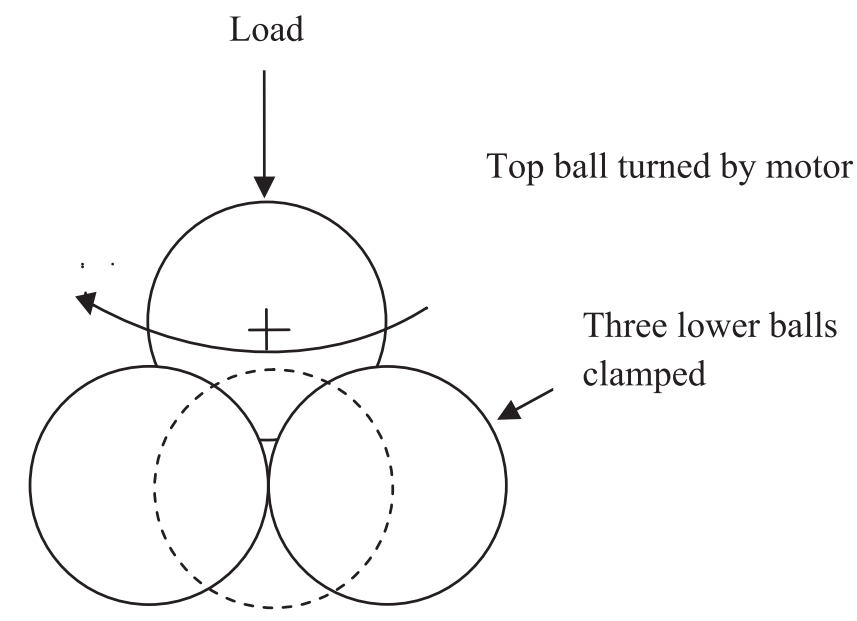

Figure 3. Schematic diagram of a four-ball wear test.

microscope capable of measuring the diameters of the scars produced on the three stationery balls to an accuracy of $0.01 \mathrm{~mm}$ manufactured by Ducom Instruments Pvt. Ltd. (India) was used.

Friction and wear experiments were conducted on a universal tribometer (Rtec, USA) with high-resolution piezo load sensor, using a pin-on-block arrangement. The piston ring pin was held fixed as upper sample, and the lower sample cylinder liner was mounted on the reciprocating drive. The schematic diagram of a universal tribometer is shown in Figure 4. All the experiments were

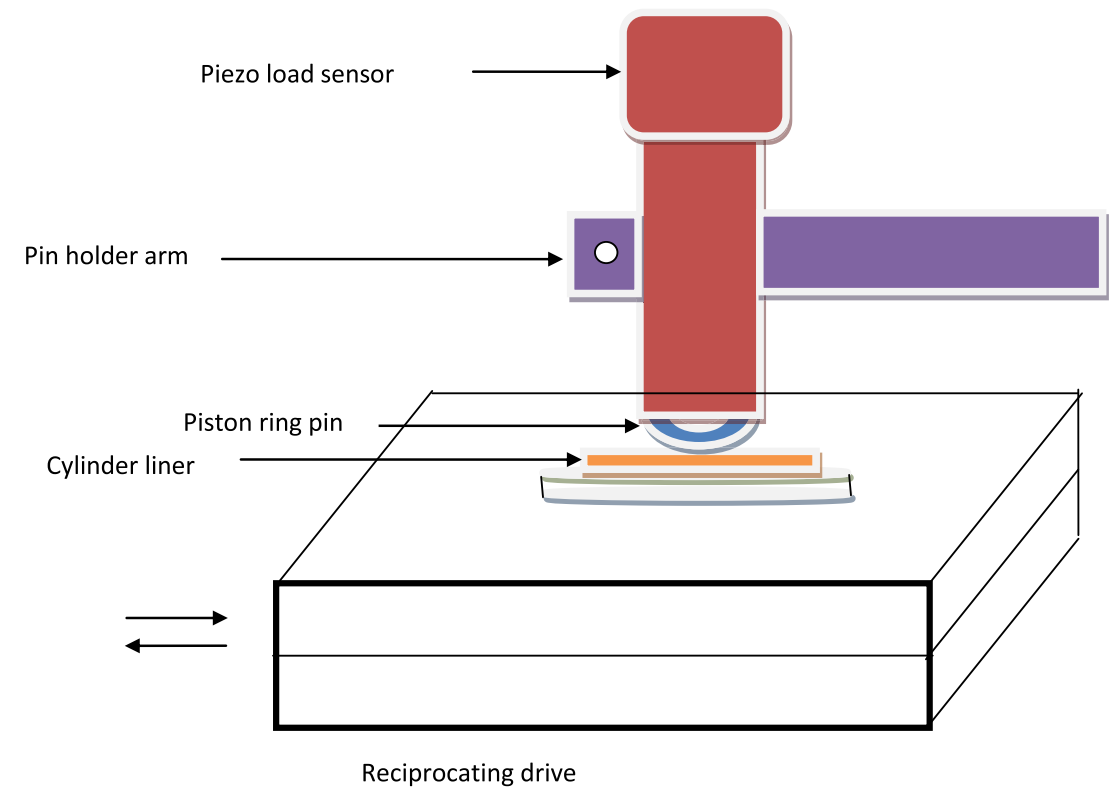

Figure 4. Schematic diagram of a universal tribometer. 
conducted at ambient temperature. The tests for friction and wear were performed at sliding velocity of $0.03 \mathrm{~m} \mathrm{~s}^{-1}$ and under normal load of $50 \mathrm{~N}, 100 \mathrm{~N}$ and $125 \mathrm{~N}$ on the contact surfaces. The length of stroke was kept $2 \mathrm{~mm}$ in all the tests, and test duration was fixed as $10 \mathrm{~min}$ for each experiment. All the friction and wear experiments were repeated three times to check for the reproducibility.

Surface morphological studies of cylinder liner and piston ring pin were conducted on scanning electron microscope Hitachi 3600 (Hitachi, Ltd., Tokyo, Japan). Invia Renishaw Raman microscope with $532 \mathrm{~nm}$ wavelength and $50 \mathrm{mv}$ laser power and 50× objective under $60 \mathrm{~s}$ exposure time with single accumulation was used to analyse the h-BN nanoparticles and the wear scar on the cylinder liner.

\section{RESULTS AND DISCUSSION}

Friction and wear tests were conducted on a four-ball wear test machine and a universal tribometer under various conditions of load and sliding velocity. These are discussed in the following sections.

\section{Film parameter}

An important parameter that indicates the effectiveness of lubrication is the film parameter, given by Charoo and Wani. ${ }^{18}$

$$
\Lambda=\frac{\mathrm{h}_{\text {min }}}{\sqrt{\mathrm{R}_{\mathrm{qa}}^{2}+\mathrm{R}_{\mathrm{qb}}^{2}}}
$$

where $h_{\text {min }}$ is the minimum film thickness and $R_{q a}$ and $R_{q b}$ is the surface roughness of the convex and concave surfaces. The film parameter is used to define the four important lubrication regimes, which include (i) boundary lubrication, $\Lambda<1$; (ii) partial lubrication, $1 \leq \Lambda<3$; (iii) hydrodynamic lubrication, $3 \leq \Lambda$; and (iv) elastohydrodynamic lubrication, $3 \leq \Lambda<10$. These values are only approximate, but give useful insight into the importance of lubrication. The minimum film thickness was calculated using Equation 3 given as follows:

$$
\mathrm{h}_{\min }=3.63 \mathrm{RU}_{\Sigma}^{0.68} \mathrm{G}_{\Sigma}^{0.49} \mathrm{~W}_{\Sigma}^{-0.073}\left(1-\mathrm{e}^{-0.68 \mathrm{k}_{\mathrm{e}}}\right)
$$

where $\mathrm{U}_{\Sigma}=\eta_{0} \mathrm{u}_{\mathrm{s}} / \mathrm{E}^{*} \mathrm{R} ; \mathrm{G}_{\Sigma}=\alpha_{\mathrm{p}} \mathrm{E}^{*} ; \mathrm{W}_{\Sigma}=\mathrm{P} / \mathrm{E}^{*} \mathrm{R}^{2}$ and $\eta_{0}$ is dynamic viscosity $\left(26.8 \times 10^{-3}\right.$ Pas $)$, $\alpha_{\mathrm{p}}$ is viscosity-pressure coefficient $3.4 \times 10^{-8} \mathrm{~Pa}^{-1}, \mathrm{R}$ is the reduced radius of curvature, $\mathrm{E}^{*}$ is reduced Young's modulus and $\mathrm{u}_{\mathrm{s}}$ is the entraining surface velocity. $\mathrm{P}$ is the normal load $(50 \mathrm{~N}$, $100 \mathrm{~N}$ and $125 \mathrm{~N}$ ), and $\mathrm{k}_{\mathrm{e}}$ is the ellipticity parameter. The calculations for all the experiments using Equations 2 and 3 gave the $\Lambda$ ratio well under unity, which means that the lubrication occurred in the boundary lubrication regime only.

\section{Wear preventive characteristics of lubricating fluid (four-ball test)}

Wear tests were conducted for both lubricant SAE 20W50 alone and lubricant SAE 20W50 using ASTM D4172 standard with $1.0 \mathrm{wt} \% \mathrm{~h}-\mathrm{BN}$ on wear testing machine. Wear scar diameter (WSD) of the three stationery balls was measured on the microscope equipped with the four-ball wear test machine. The results are shown in the Table III. Wear scar diameter of the balls with lubricant SAE $20 \mathrm{~W} 50$ alone were greater than the WSD of the balls in lubricant SAE $20 \mathrm{~W} 50+1.0 \mathrm{wt} \% \mathrm{~h}-\mathrm{BN}$. There 
was reduction of almost $20 \%$ in the WSD of the ball with h-BN nanoparticles as additive in the lubricant. More or less, similar results were obtained with $2.0 \mathrm{wt} \%$ and $3.0 \mathrm{wt} \%$ of h-BN nanoparticles as additive in SAE 20W50. However, $4.0 \mathrm{wt} \%$ of h-BN nanoparticles as additive did not yield any significant result, which may be due to agglomeration of the nanoparticles preventing them to enter the contact zone. These findings were encouraging to carry out further studies in practical applications such as piston ring and cylinder liner in an IC engine. This was probably due to the protective layer formed by the reaction of h-BN nanoparticles on the surface of the balls resulting in reduction of the wear scar.

Table III. The WSD value achieved under test conditions of $392 \mathrm{~N}, 1200 \mathrm{rmin}^{-1}, 75^{\circ} \mathrm{C}$ and $60 \mathrm{~min}$ (ASTM D 4172).

\begin{tabular}{llllr}
\hline & \multicolumn{4}{c}{ WSD in $\mu \mathrm{m}$} \\
Ball no. \\
\cline { 2 - 5 } Lubricant & 1 & 2 & 3 & Average \\
\hline SAE 20W50 & 567.15 & 575.45 & 571.28 & 571.29 \\
SAE 20W50+1.0 wt\% h-BN & 452.56 & 465.52 & 461.36 & 459.81 \\
\hline
\end{tabular}

h-BN: hex-boron nitride.

WSD: wear scar diameter.

SAE, Society of Automotive Engineers.

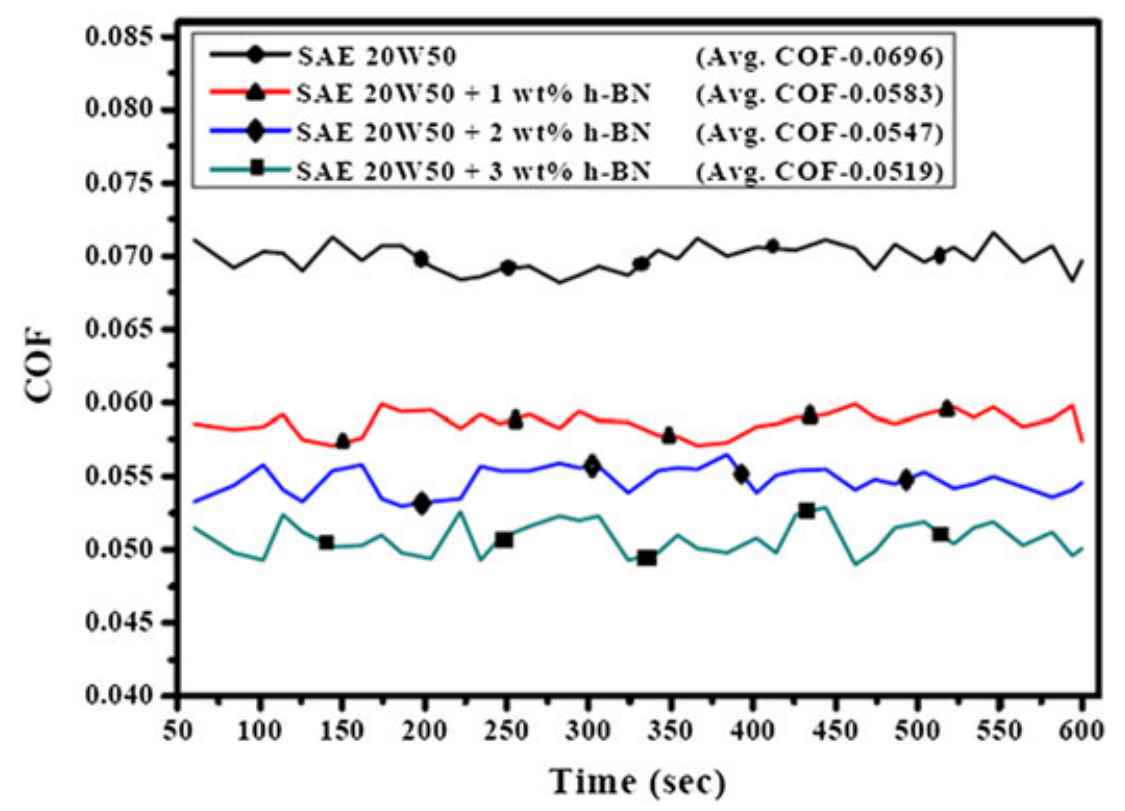

Figure 5. Coefficient of friction (COF) obtained with and without hex-boron nitride (h-BN; wt \%) nanoparticles as additive in the lubricant Society of Automotive Engineers (SAE) 20W50 at the normal load of $50 \mathrm{~N}$ and sliding speed of $0.03 \mathrm{~m} \mathrm{~s}^{-1}$. 
Friction and wear studies of cylinder liner and piston ring pin

Coefficient of friction (COF) and wear observed in a tribo-pair of representative geometry of cylinder liner and piston ring with h-BN nanoparticles added in base engine oil of grade SAE 20W50 in different concentration (wt\% 1.0, 2.0 and 3.0) in all reciprocating sliding experimental studies at various loads are shown in Figures 5-7.

Coefficient of friction. Figures 5, 6 and 7 show the variation of COF with time for normal load of $50 \mathrm{~N}, 100 \mathrm{~N}$ and $125 \mathrm{~N}$, respectively. These tests were conducted at sliding velocity of $0.03 \mathrm{~m} \mathrm{~s}^{-1}$ for duration of $10 \mathrm{~min}$. It is evident from these figures that $\mathrm{COF}$ increased with increase in normal load for lubricant without additive. However, a different behaviour was observed with h-BN nanoparticles as additive in SAE 20W50. The COF decreased with an increase in the concentration of h-BN nanoparticles in the lubricant; lowest COF of 0.0401 was observed for the lubricant SAE $20 \mathrm{~W} 50+3.0 \mathrm{wt} \% \mathrm{~h}-\mathrm{BN}$ at $100 \mathrm{~N}$ load, and highest COF of 0.0712 was observed for the lubricant SAE 20W50 at normal load of $125 \mathrm{~N}$. It is also evident from Figures 5-7 that COF is affected by normal load and concentration of the nanoparticles in the lubricant. Similar results are reported in the literature. ${ }^{3,19}$

The decrease in COF with h-BN nanoparticles as additive in SAE 20W50 has not been reported before in literature, and a possible mechanism for such a phenomenon is that during sliding, solid nanoparticles of h-BN are believed to be carried into the contact zone by the liquid lubricant. In the contact zone, these nanoparticles are smeared on the actual contact spots to form a very thin boundary

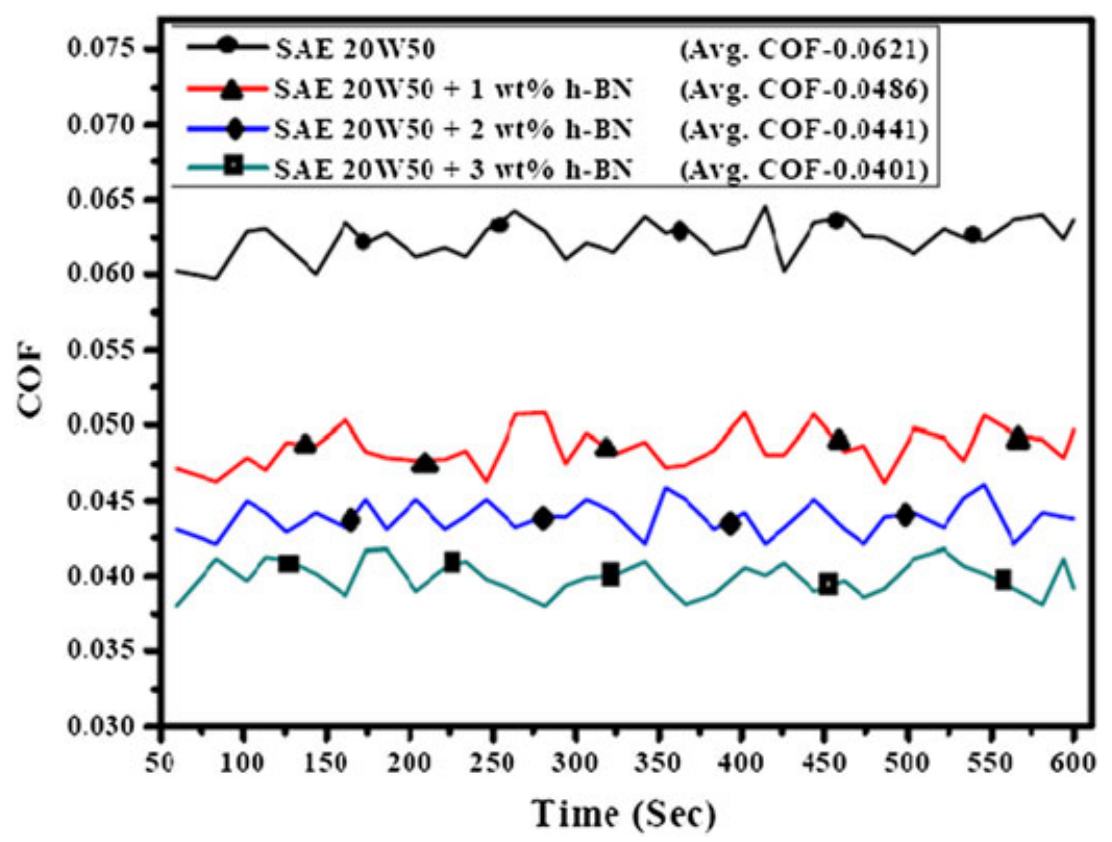

Figure 6. Coefficient of friction (COF) obtained with and without hex-boron nitride (h-BN; wt\%) nanoparticles as additive in the lubricant Society of Automotive Engineers (SAE) 20W50 at the normal load of $100 \mathrm{~N}$ and sliding speed of $0.03 \mathrm{~m} \mathrm{~s}^{-1}$. 


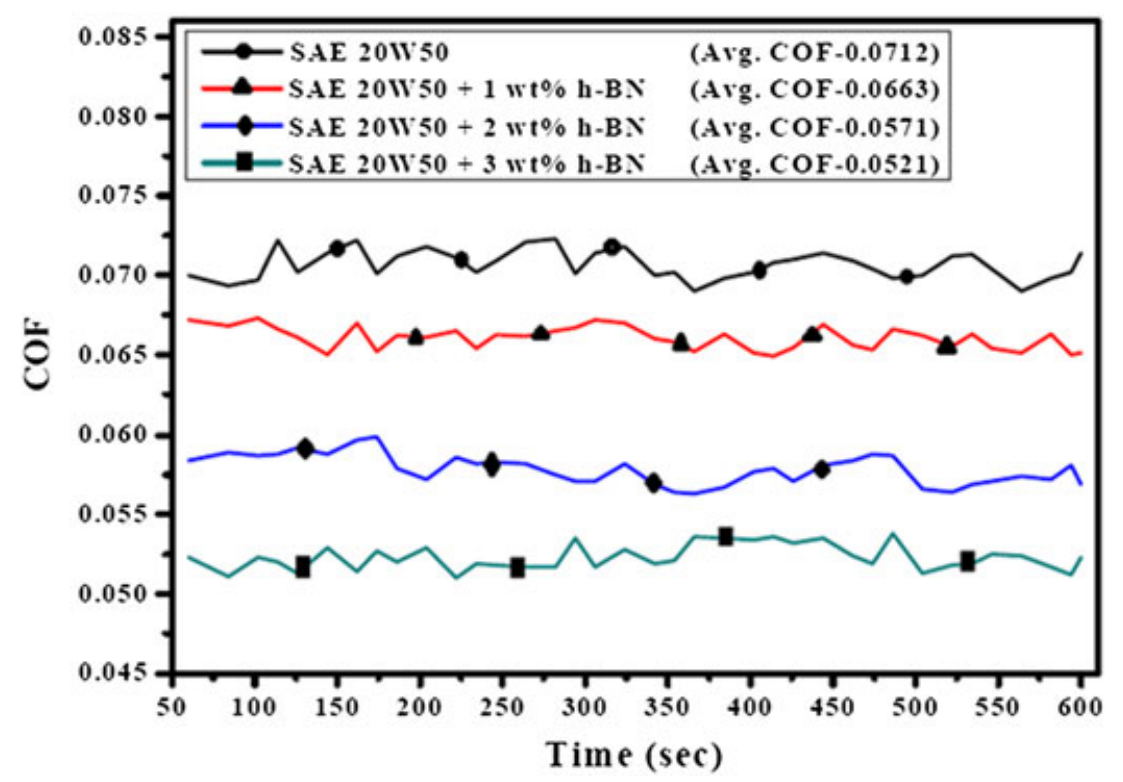

Figure 7. Coefficient of friction (COF) obtained with and without hex-boron nitride (h-BN; wt \%) nanoparticles as additive in the lubricant Society of Automotive Engineers (SAE) 20W50 at the normal load of $125 \mathrm{~N}$ and sliding speed of $0.03 \mathrm{~m} \mathrm{~s}^{-1}$.

film, the thickness of this film being of the order of few nanometers. The nanoparticles of h-BN having high chemical affinity react with these contact spots and form a protective layer on the contact surface of the cylinder liner-piston ring pin tribo-pair. This is attributed to the graphite-like layered structure of the h-BN between the layers, and the lubrication mechanism of h-BN is the result of free movement of adjacent layers under sliding. ${ }^{2,20}$ These results are supported by Raman spectroscopy conducted on h-BN nanoparticles and the wear scar on cylinder liner, observed for the lubricant SAE $20 \mathrm{~W} 50+3.0 \mathrm{wt} \% \mathrm{~h}-\mathrm{BN}$ at $125 \mathrm{~N}$ load as shown in Figures 8 and 9, respectively. Refined data are with baseline correction. Laser power (100\%) was used. WiRE 4.1 software was used to acquire and analyse the data. The nanoparticles of h-BN represent two peaks at 1334 and $1366 \mathrm{~cm}^{-1}$, and wear scar on cylinder liner also represents two peaks at 1331 and $1364 \mathrm{~cm}^{-1}$, respectively, which is in agreement with the available literature. ${ }^{16}$ This analysis clearly shows the formation of tribofilm on the contact surface protecting it against wear and enhancing the anti-friction properties of the lubricant SAE 20W50.

Wear of cylinder liner and piston ring pin tribo-pair. The quantitative wear loss of the cylinder liner by piston ring pin is shown in Figure 10 at various loads under lubrication with SAE 20W50 and SAE 20W50 + h-BN nanoparticles $(1.0 \mathrm{wt} \%, 2.0 \mathrm{wt} \%$ and $3.0 \mathrm{wt} \%)$ at $0.03 \mathrm{~m} \mathrm{~s}^{-1}$ sliding velocity. It is evident from these results that in most of the cases, the wear of cylinder liner decreased with the increase in concentration of h-BN nanoparticles in SAE 20W50. Lowest wear of $0.011 \mathrm{~mm}^{3}$ was obtained at a normal load of $50 \mathrm{~N}$ for sliding velocity of $0.03 \mathrm{~mm} \mathrm{~s}^{-1}$ with $3.0 \mathrm{wt} \%$ concentration of h-BN nanoparticles in SAE 20W50. Highest wear of $0.04 \mathrm{~mm}^{3}$ was obtained at all loads without 


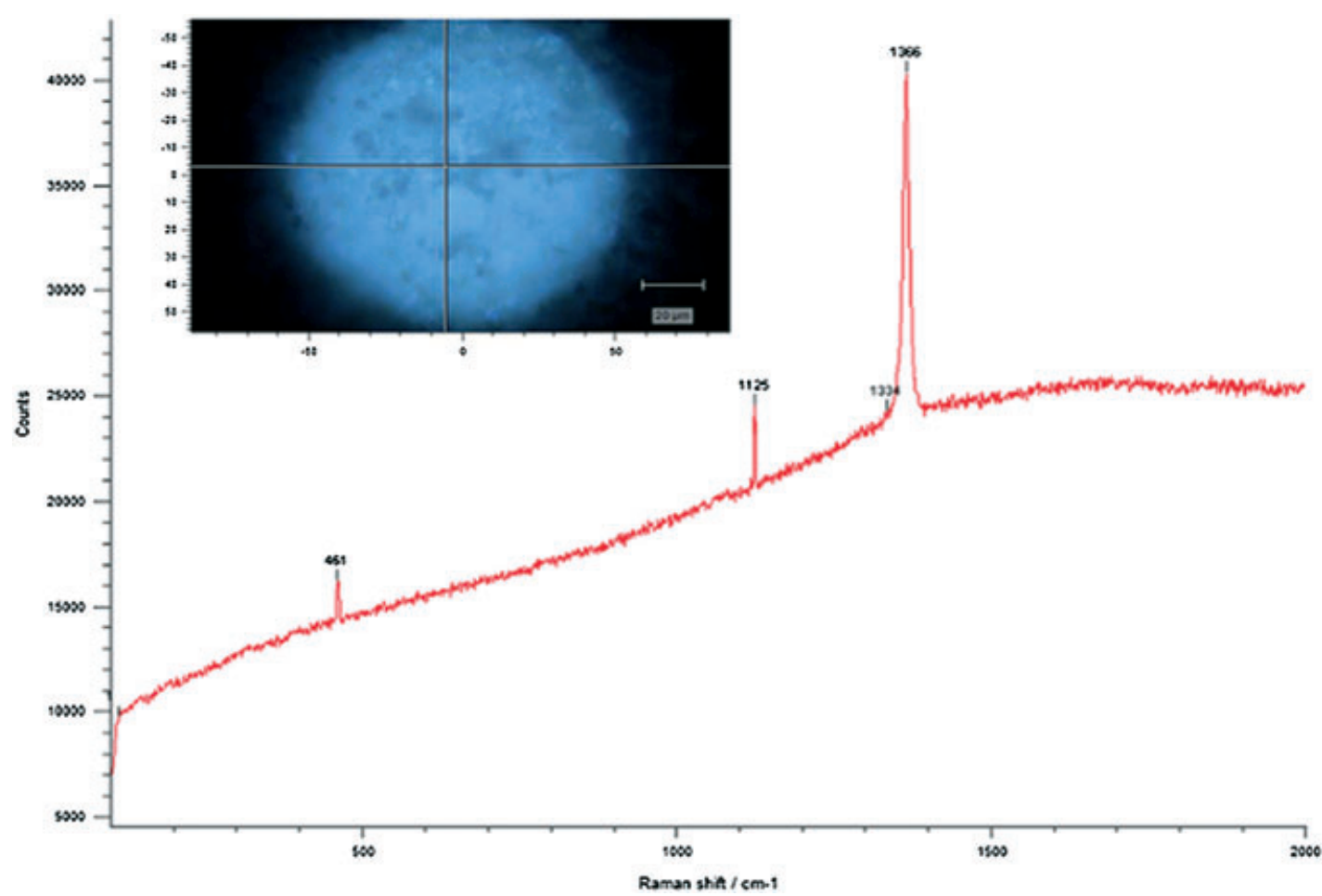

Figure 8. Raman spectrum of the hex-boron nitride nanopowder (in the frame) obtained using a green laser $(\lambda=532 \mathrm{~nm})$.

additive in SAE 20W50. It is inferred from these results that h-BN nanoparticles as additive reduced the wear loss of about $30-70 \%$ in comparison to lubricant without additive. However, in all tests, negligible wear was observed on piston ring pin, which is attributed to higher wear resistance of pin material due to its higher hardness (1190 HV) value, as the piston ring pin is chromium coated, in comparison to cylinder liner hardness (630 HV).

As is clear from Figure 9 (in the frame), h-BN nanoparticles form a boron-rich boundary film on the surface of the cylinder liner. This film then shears easily to provide low friction. Because of its protective nature, the boron-rich boundary film reduces wear also. In short, h-BN nanoparticles offer unique opportunities in meeting the increasingly more stringent operating conditions of future tribological systems.

Scanning electron microscope micrographs of cylinder liner and piston ring pin, before and after friction, and wear tests are shown in Figures 11 and 12, respectively. It is evident from Figure 12a that loss of material on the cylinder liner has occurred resulting in rough wear tract, whereas no such phenomenon has been observed on the wear tract of piston ring pin as shown in Figure 12b. It is also evident from the comparison of Figures 11a and 12a that graphite flakes present on unworn surface of the cylinder liner have been removed, which interprets higher wear of the cylinder liner. These results are also supported by 3D surface profiles of the wear tract on cylinder liner without and with h-BN additive in SAE 20W50 as shown in Figure 13. 


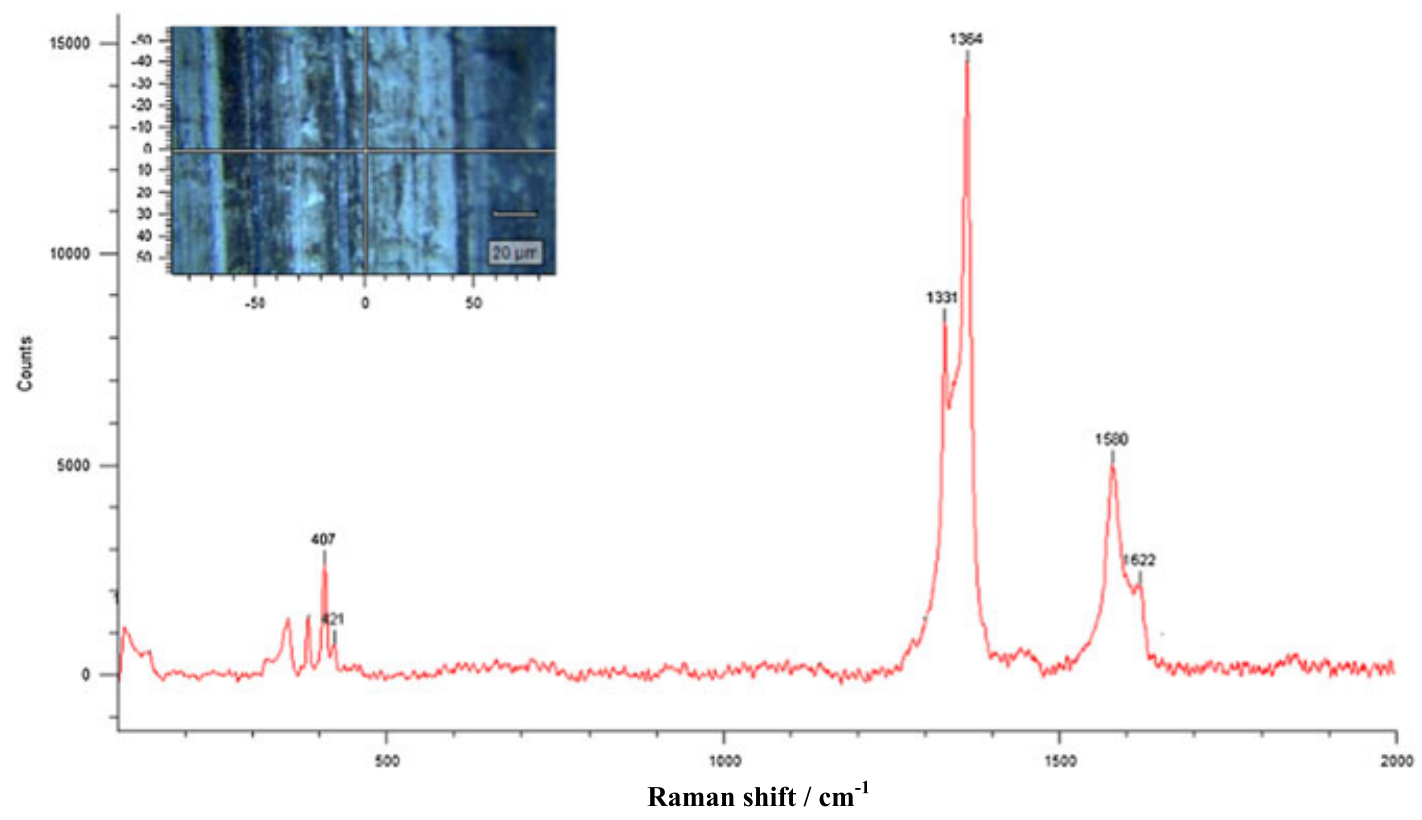

Figure 9. Raman spectrum of the wear scar (in the frame) on cylinder liner obtained using a green laser $(\lambda=532 \mathrm{~nm})$.

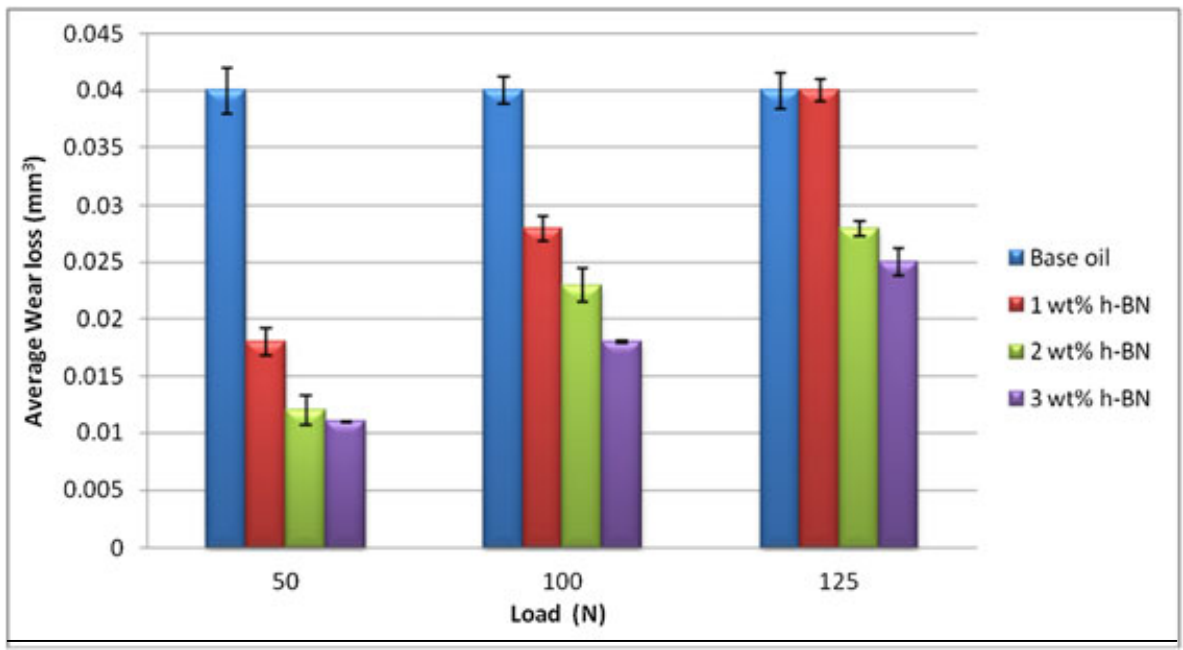

Figure 10. Wear loss versus load on cylinder liner at sliding velocity of $0.03 \mathrm{~m} \mathrm{~s}^{-1}$ at various concentrations of hex-boron nitride (h-BN) as additive in Society of Automotive Engineers (SAE) 20 W50. 

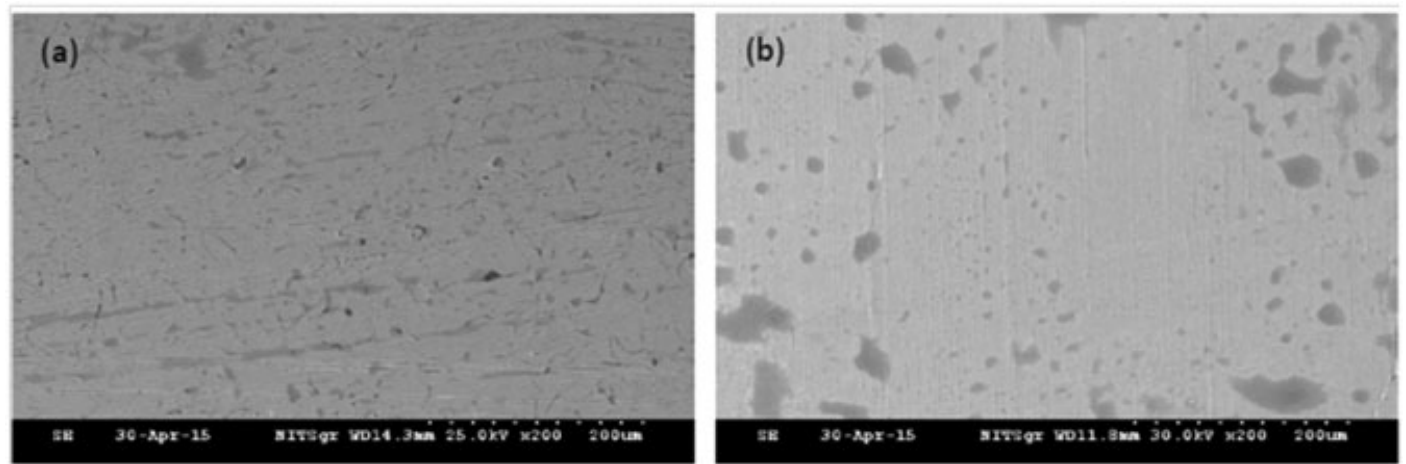

Figure 11. Scanning electron microscope micrographs of a (a) cylinder liner and (b) a piston ring pin before friction and wear test.
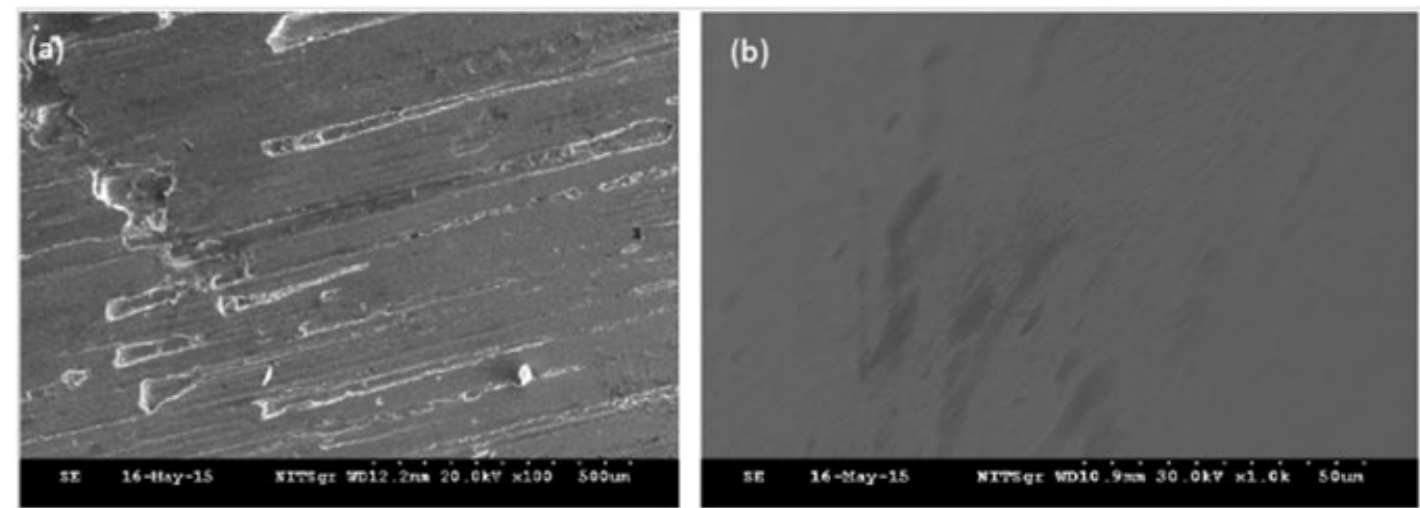

Figure 12. Scanning electron microscope micrographs of wear tract after the friction and wear test with Society of Automotive Engineers 20W50 + 3.0 wt \% hex-boron nitride nanoparticles: (a) Cylinder liner and (b) piston ring pin.

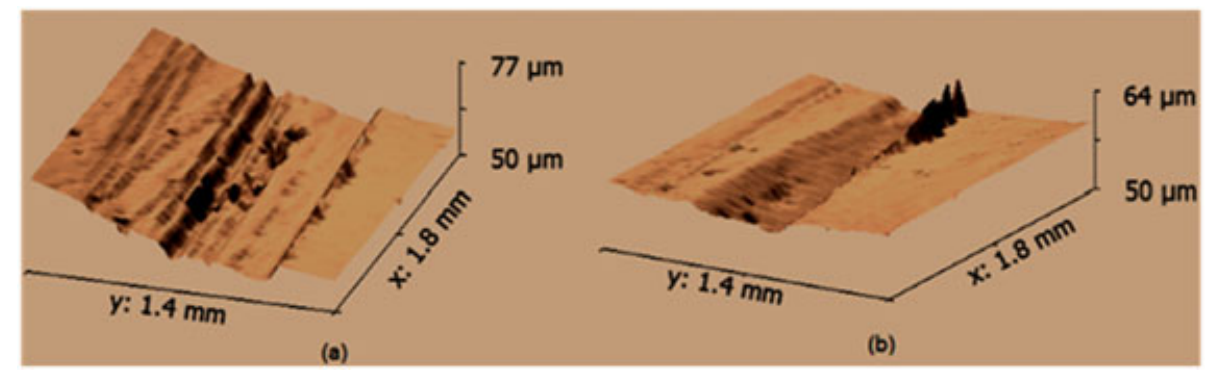

Figure 13. 3D surface profiles of wear tract after the friction and wear test on cylinder liner at $50 \mathrm{~N}$ normal load with (a) SAE 20W50 and (b) SAE 20W50+3.0 wt $\%$ hex-boron nitride nanoparticles. 


\section{TRIBOLOGICAL PROPERTIES OF H-BN NANOPARTICLES AS LUBRICANT ADDITIVE}

\section{CONCLUSIONS}

Effect of various concentrations of h-BN nanoparticles as additive in conventional lubricant SAE 20W50 on friction and wear on piston ring pin and cylinder liner tribo-pair have been studied. The results show that friction and wear of piston ring pin and cylinder liner tribo-pair strongly depend on the concentration of h-BN nanoparticles in the lubricant SAE 20W50. Use of h-BN nanoparticles as additives in SAE 20W50 greatly increased the anti-friction and anti-wear properties of the lubricant. Four-ball wear preventive test showed 20\% decrease in the WSD of the balls with h-BN nanoparticles as additive in the lubricant SAE 20W50. The minimum value of coefficient of friction (0.0401) was observed at $3.0 \mathrm{wt} \%$ of h-BN under normal load of $100 \mathrm{~N}$ at sliding velocity $0.03 \mathrm{~m} \mathrm{~s}^{-1}$. Friction and wear tests on tribometer revealed that $\mathrm{h}-\mathrm{BN}$ nanoparticles as additive reduced the wear loss of about $30-70 \%$, in comparison to lubricant without additive at all sliding velocities. The COF and wear is a function of concentration of the nanoparticles in the lubricant.

\section{REFERENCES}

1. Zhang W, Chen S, Liu W, Yu L. Friction and wear behaviour of Sialon/(Ca, Mg)-Sialon with lubrication by coated PbS nanoparticles as oil additives. Lubrication Science 2006; 16(1):47-56.

2. Xiaodong Z. Study on the tribological properties of surfactant-modified h-BN Micrometer spheres as an additive in liquid paraffin. Tribology International 2007; 40:863-868.

3. Pawlak Z, Kaldonski T, Pai R, Bayraktar E, Oloyede A. A comparative study on the tribological behavior of hexagonal boron nitride (h-BN) as lubricant micro particles - An additive in porous sliding bearings for a car clutch. Wear 2009; 267:1198-1202.

4. Deorsola F, Blengini N, Fino G. Synthesis, characterization and environmental assessment of nanosized H-BN particles for lubricants applications. Chemical Engineering Journal 2012; 195-196:1-6.

5. Zhu L. Microstructure and tribological properties of WS2/IF-H-BN multilayer films. Applied Surface Science 2012; 258:1944-1948.

6. Kalin M. Mechanisms and improvements in the friction and wear behavior using H-BN nano-tubes as potential oil additives. Wear 2012; 280- 281:36-45.

7. Shuying G. Solvent-free ionic molybdenum disulfide $\left(\mathrm{MoS}_{2}\right)$ nano fluids with self-healing lubricating behaviors. Materials Letters 2013; 97:169-172.

8. Kogovsek J. Influence of surface roughness and running-in on the lubrication of steel surfaces with oil containing IF-H-BN nano tubes in lubrication regimes. Tribology International 2013; 61:40-47.

9. Khan Z, Pasheai P, Bajwa R, Nazir M, Cakmak M. Fabrication and characterization of electrodeposited and magnetronsputtered thin films. Int. J. Comp. Meth. and Exp. Meas. 2015; 3(2):165-174.

10. Pejakovic V, Kalin M. Frictional behaviour of imidazolium sulphate ionic liquid additives under mixed slide-to-roll conditions: part 1 - Variation of mixtures with identical weight ratio of ionic liquid additive. Lubrication Science 2014; 27(8):463-477.

11. Rapoport L, Leshchinsky V, Lapsker I, Volovik Y, Nepomnyashchy O, Lvovsky M, Popovitz-Biro R, Feldman Y, Tenne R. Tribological properties of $\mathrm{WS}_{2}$ nano-particles under mixed lubrication. Wear 2003; 255:785-793.

12. Wu YY, Liu WC. Experimental analysis of tribological properties of lubricating oils with nanoparticle additives. Wear 2007; 262:819-825.

13. Chang $\mathrm{H}$. Tribological property of $\mathrm{TiO}_{2}$ nanolubricants on piston and cylinder surfaces. Journal of Alloys and Compounds 2010; 495:481-484

14. Pejakovic V, Kalin M. Frictional behaviour of imidazolium sulphate ionic liquid additives under mixed slide to roll conditions: part 2 - influence of concentration and chemical composition of ionic liquid additive. Lubrication Science 2014; 27(8):489-503.

15. Nicholaos GD. Tribological studies of coated pistons sliding against cylinder liners under laboratory test conditions. Lubrication Science 2012; 24(5):216-227.

16. Nicholaos GD, Elena T, Joules R, George F. Tribological effects of $\mathrm{BN}$ and $\mathrm{WS}_{2}$ nanoparticles added to polyalphaolefin oil in piston skirt/cylinder liner tests. Tribology Letters 2012; 47:91-102. 


\section{S. CHAROO AND M. F. WANI}

17. Martin JM, Ohmae N. Nanolubricants [M]. John Wiley and sons, Ltd, England 2008.

18. Charoo MS, Wani MF. Friction and wear properties of nano- $\mathrm{Si}_{3} \mathrm{~N}_{4} /$ nano-SiC composite under nanolubricated conditions. Journal of advanced ceramics. 2016; 5(2):145-152.

19. Cho DH, Kim JS, Kwon SH, Lee C, Lee YZ. Evaluation of hexagonal boron nitride nano-sheets as a lubricant additive in water. Wear 2013; 302:981-986.

20. Wan Q, Jin Y, Sun P, Ding Y. Tribological behaviour of a lubricating oil containing boron nitride nanoparticles. Procedia Engineering. 2015; 102:1038-1045. 